\title{
Power Control with Static Synchronous Series Compensator for Distribution Network integrating Wind Farm based on DFIGs
}

\author{
O. Aouchenni ${ }^{1}$, R. Babouri ${ }^{1}$, D, Aouzellag ${ }^{1}$, F. Chabour ${ }^{2}$ and C. Nichita ${ }^{2}$ \\ ${ }^{1}$ Laboratoire de Maitrise des Energies Renouvelables, université de BEJAIA, (Algeria) \\ Phone/Fax number: +00 33673989 181, e-mail: aouchenni.ounissa@gmail.com \\ ${ }^{2}$ Groupe de Recherche en Electrotechnique et Automatique, GREAH Lab, université du Havre, (France)
}

\begin{abstract}
This paper describes an approach powers flow control for an electrical network connected with a wind farm. In this work the powers flow control are performed through a Static Synchronous Series Compensator (SSSC) which is one of among Flexible AC Transmission System devices (FACTS). The wind farm is based on doubly-fed induction generators (DFIG). The simulation results show the effectiveness of the proposed approach making better the damping of power oscillations caused by the wind farm, ensuring the minimizing system transmission losses while providing a best voltage level. The simulations are done in MATLAB/ Simulink/ SimPowerSystems environment.
\end{abstract}

\section{Key words}

DFIG, wind generation, SSSC, power flow control.

\section{Introduction}

The high penetration of wind power into the power systems, which were traditionally built around large synchronous generators, may give rise to power quality and stability problems caused by the fluctuating nature of the wind. Due to the increase in wind power generation, the impact of the disturbances introduced by this technology has to be considered [1]-[2]-[3]. Recently, wind energy is the most common and viable option for most generation power. This is because wind energy generation has many advantages like very large number of potential sites for wind farm installation and rapid development of various technologies of wind power generation. There are various of generator designs that are used in wind turbines [4]. Applications of the power electronics devices in power systems are very much augmented. The FACTS devices are introduced in the power system transmission for the reduction of the transmission line losses, Increases Power System Stability and also to increase the transfer capability. FACTS controllers are a power electronic device which is used to enhance controllability and increase power transfer capability. It is mainly used for solving various power system steady state control problems, enhancement of voltage stability and transient stability. The FACTS controllers are capable of supplying/absorption of reactive power [5]. A SSSC is a series controller of FACTS family and is connected in series with an electrical line. The SSSC controller mainly depends on the output amplitude of voltage source converter (VSC). SSSC is increasingly applied by the utilities in modern power systems. SSSC has several advantages over the conventional one due to its storage element. Also, the main control objective of the SSSC is to directly control the current and indirectly the power flowing through the line by controlling the reactive power exchange between the SSSC and the AC system [6]. The SSSC circuit model has a voltage source converter (VSC), DC capacitor and a coupling transformer. This transformer is connected in series with power system which couples the SSSC with the electrical line [7]. SSSC as series FACTS device has a DC capacitor in structure of voltage inverter and delivers a balanced synthesized three-phase voltage to the electrical network. Although about this voltage in order to have only reactive power exchange with the network, it should be perpendicular to the current line. In fact, if this voltage has a phase priority relative to the current, the VSC acts like an inductive and if it has a phase lag, it acts such a capacitor [8]. The main objective of this work is the active and reactive power control of an electrical network integrating a wind farm based on DFIGs. The power quality can be improved using the SSSC which is one of the types of FACTS controllers examined in this paper. Furthermore, the proposed method is able to improve reactive power compensation and to increase the power transmission limit. This method also realizes a damping of power oscillation caused by wind energy production.

\section{Wind generator model}

A modeling methodology of torque and power characteristics for a wind turbine allows to:

- Generate the power coefficient characteristics as a function of the speed ratio $\lambda$ and the pitch angle of blades $\beta$ :

$$
C_{P}=C_{P}(\lambda, \beta)
$$


-Generate the available wind power Pt as a function of the wind speed $V_{w}$, the rotation speed $\Omega_{t}$ and the pitch angle of blades $\beta$ :

$$
P_{t}=P_{t}\left(V_{w}, \Omega_{t}, \beta\right)
$$

-calculate the available turbine torque $\mathrm{T}_{t}$ as a function of the wind speed $V_{\mathrm{w}}$, the rotation speed $\Omega_{\mathrm{t}}$ and the pitch angle of blades $\beta$ :

$$
\mathrm{T}_{\mathrm{t}}=\mathrm{T}_{\mathrm{t}}\left(\mathrm{V}_{\mathrm{w}}, \Omega_{\mathrm{t}}, \beta\right)
$$

In this work pitch angle $\beta$ is fixed to $0(\beta=0)$. Figure 1 shows power coefficient and figure 2 shows the wind power for variable wind speed [9].

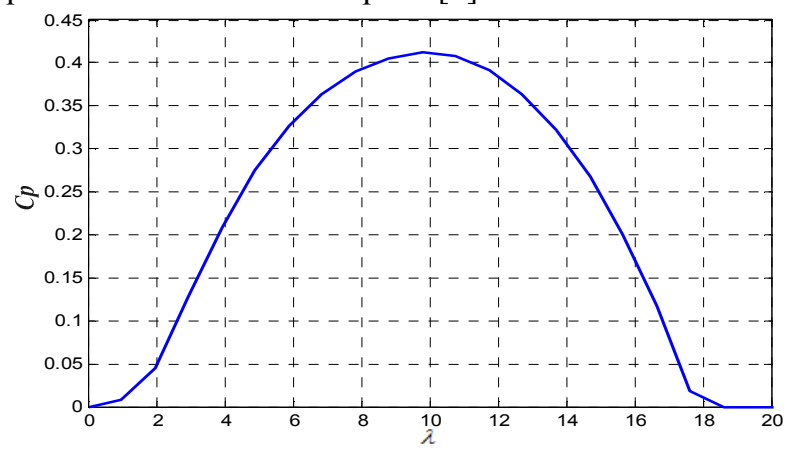

Fig. 1. Power coefficient.

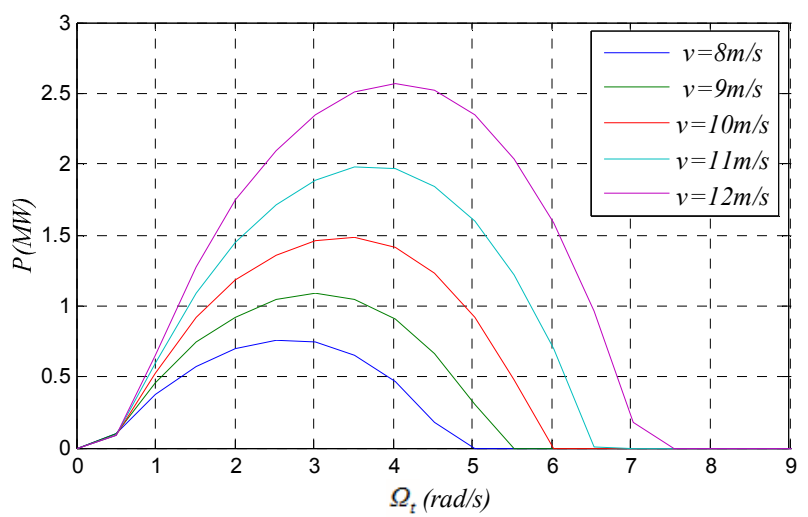

Fig. 2. Wind power for variable wind speed.

\section{DFIG model and vector control}

The classical electrical equations of the DFIG in the PARK frame are written as follows:

$$
\left\{\begin{array}{l}
\mathrm{v}_{\mathrm{sd}}=\mathrm{R}_{\mathrm{s}} \mathrm{i}_{\mathrm{sd}}+\mathrm{s} \varphi_{\mathrm{sd}}-\omega_{\mathrm{s}} \varphi_{\mathrm{sq}} \\
\mathrm{v}_{\mathrm{sq}}=\mathrm{R}_{\mathrm{s}} \mathrm{i}_{\mathrm{sq}}+\mathrm{s} \varphi_{\mathrm{sq}}+\omega_{\mathrm{s}} \varphi_{\mathrm{sd}} \\
\mathrm{v}_{\mathrm{rd}}=\mathrm{R}_{\mathrm{r}} \mathrm{i}_{\mathrm{rd}}+\mathrm{s} \varphi_{\mathrm{rd}}-\left(\omega_{\mathrm{s}}-\omega\right) \varphi_{\mathrm{rq}} \\
\mathrm{v}_{\mathrm{rq}}=\mathrm{R}_{\mathrm{r}} \mathrm{i}_{\mathrm{rq}}+\mathrm{s} \varphi_{\mathrm{rq}}+\left(\omega_{\mathrm{s}}-\omega\right) \varphi_{\mathrm{rd}}
\end{array}\right.
$$

Where $R_{S}$ and $R_{r}$ are, respectively, the stator and rotor phase resistances.

$\omega=$ p. $\Omega_{\text {mec }}$ is the electrical speed, $p$ is the number of pair pole and $s$ is Laplace operator. In our case we choose the direction of reference $(\mathrm{d}, \mathrm{q})$ according to the direct stator flux vector $\varphi_{\text {sd }}$, so the model of steady DFIG will be simplified as follows [5]:

$$
\left\{\begin{array}{l}
\mathrm{v}_{\mathrm{sd}}=\mathrm{R}_{\mathrm{sd}} \mathrm{i}_{\mathrm{sd}} \\
\mathrm{v}_{\mathrm{sq}}=\mathrm{R}_{\mathrm{s}} \mathrm{i}_{\mathrm{sq}}+\omega_{\mathrm{s}} \varphi_{\mathrm{sd}} \\
\mathrm{v}_{\mathrm{rd}}=\mathrm{R}_{\mathrm{r}} \mathrm{i}_{\mathrm{rd}}-\omega_{\mathrm{r}} \varphi_{\mathrm{rq}} \\
\mathrm{v}_{\mathrm{rq}}=\mathrm{R}_{\mathrm{r}} \mathrm{i}_{\mathrm{rq}}+\omega_{\mathrm{r}} \varphi_{\mathrm{rd}}
\end{array}\right.
$$

Such as:

$$
\omega_{\mathrm{r}}=\omega_{\mathrm{s}}-\omega
$$

\section{Static Synchronous Series Compensator (SSSC)}

SSSC is connected in series with a power system. It has a voltage source converter serially connected to a transmission line through a transformer. It can be considered as synchronous voltage source as it can inject an almost sinusoidal voltage of variable and controllable amplitude and phase angle, in series with the electrical line. The injected voltage is almost in quadrature with the line current. A small part of the injected voltage that is in phase with the line current provides the losses in the inverter. Most of the injected voltage, which is in quadrature with the line current, provides the effect of inserting an inductive or capacitive reactance in series with the transmission line. The variable reactance influences the electric power flow in the transmission line [6]. Figure 3 shows the functional model of SSSC which includes an energy storage device as dc capacitor in order to allow power exchanges like real or reactive power with the electrical network.

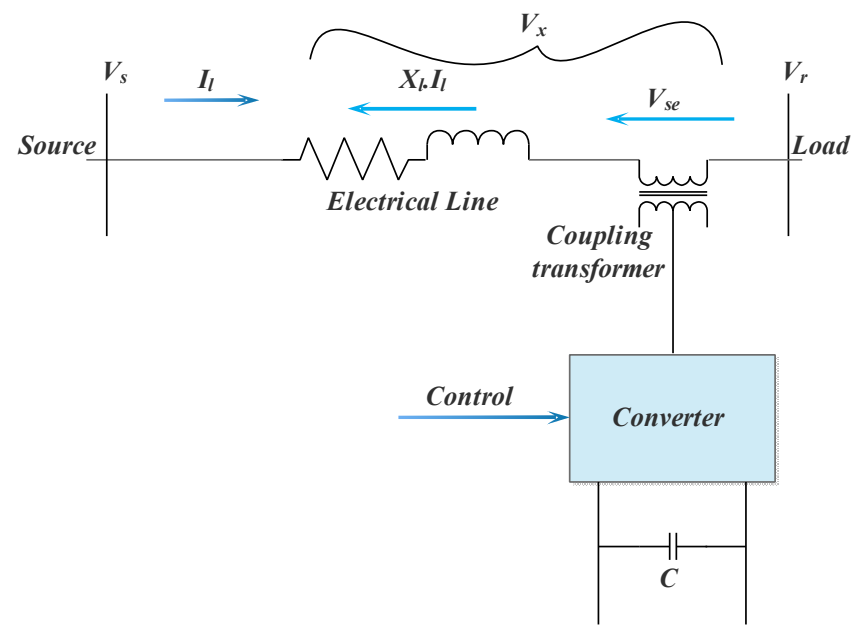

Fig. 3. Functional model of SSSC.

\section{SSSC control structure}

The SSSC produces a voltage with different magnitudes in quadrature $\left( \pm 90^{\circ}\right)$ with line current. There can be a capacitive reactance or an inductive reactance depending upon the injected voltage so that the line resistance of the total transmission line and power flow will increase or decrease. Voltage compensation mode, the SSSC can maintain the rated capacitive and inductive compensating voltage regardless of the changes in the line current. In impedance compensation mode, the SSSC must maintain the maximum rated capacitive compensating reactance at any line current. The rating of the SSSC power components must be rated for the maximum line current and compensating voltages. We can explain the various modes of capacitive and inductive compensation in this referring to the vectorial diagram of the figure 4 by admitting the equivalent diagram of a SSSC installed in a simple electrical network represented on the figure 3 [3], [12], [13]. 


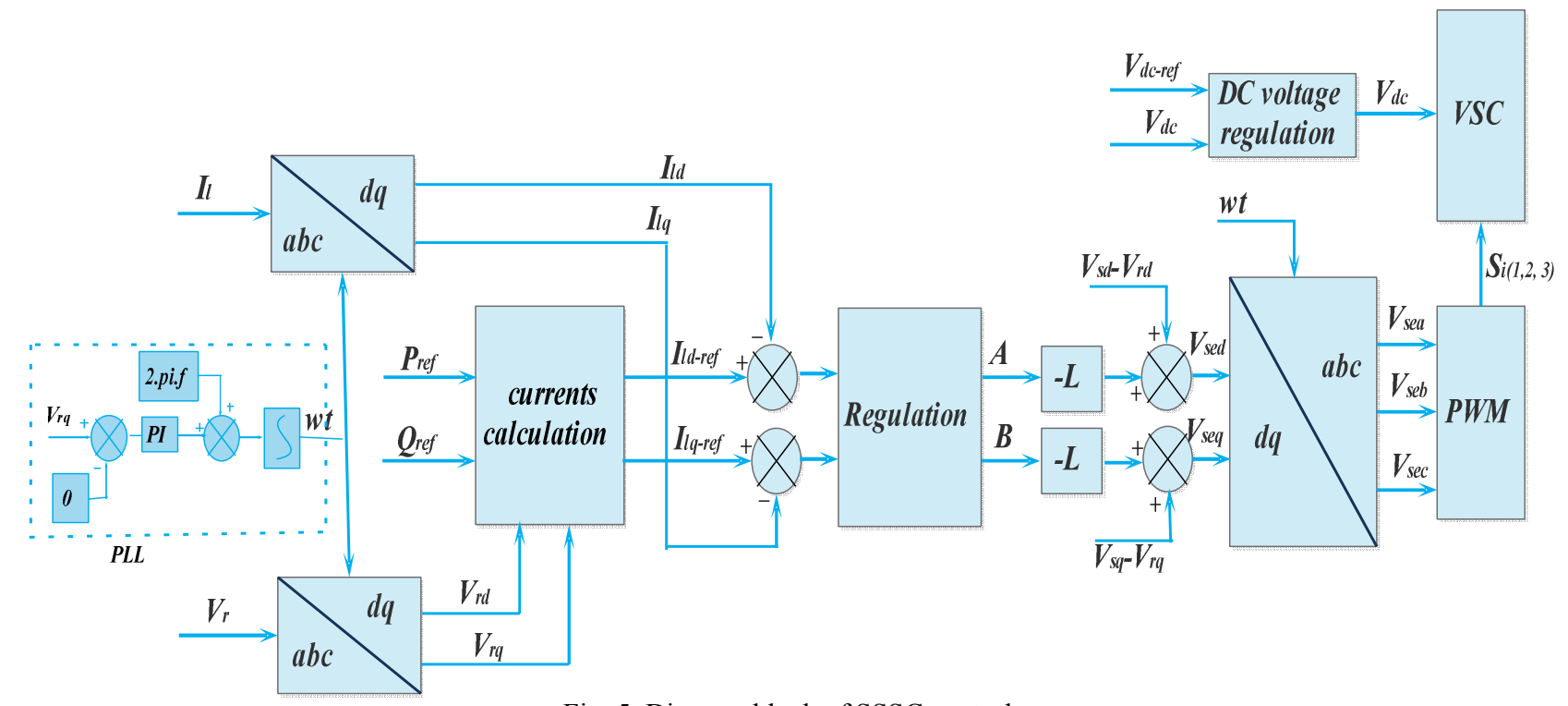

Fig. 5. Diagram block of SSSC control.

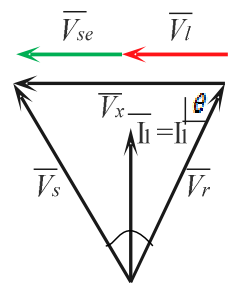

Inductive compensation $\bar{V}_{s e}=V_{q}(\underline{[e+90)}$

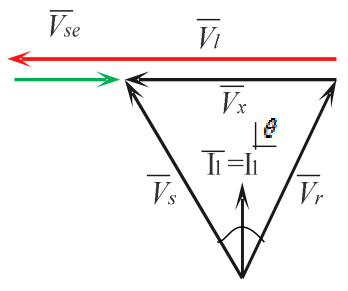

Capacitive compensation $V_{s e}=V_{q} \mid(\theta-90)$

Fig. 4. Phasor diagram of different operating modes for SSSC.

We can apply a control by decoupling currents $\mathrm{I}_{\mathrm{ld}}$ and $\mathrm{I}_{\mathrm{lq}}$ as follow [14]:

$$
\begin{aligned}
& A=\frac{1}{L}\left(V_{\text {sd }}-V_{\text {rd }}-V_{\text {sed }}\right) \\
& A=\left(K_{P}+\frac{K_{i}}{S}\right)\left(I_{l d-r e f}-I_{l d}\right)-\omega I_{l q} \\
& B=\frac{1}{L}\left(V_{s q}-V_{r q}-V_{\text {seq }}\right) \\
& B=\left(K_{P}+\frac{K_{i}}{S}\right)\left(I_{l q-r e f}-I_{l q}\right)+\omega I_{l d}
\end{aligned}
$$

A and B are the outputs of the PI controllers of the two currents $\mathrm{I}_{\mathrm{ld}}$ and $\mathrm{I}_{\mathrm{lq}}$ supplemented by under compensation $\left(-\omega \mathrm{I}_{\mathrm{lq}}\right)$ and $\left(\omega \mathrm{I}_{\mathrm{ld}}\right)$ respectively.

$$
\begin{aligned}
& I_{l d-r e f}=\frac{2}{3} \frac{P_{r}}{V_{r d}} \\
& I_{l q-r e f}=\frac{2}{3} \frac{Q_{r}}{V_{r d}}
\end{aligned}
$$

$P_{\text {ref }}$ and $Q_{\text {ref }}$ are the powers desired in the electrical line [14]. The diagram block of control is represented on the figure 5 .

\section{Studied system configuration}

The wind farm consists of ten 1.5 MW induction generators connected to $63 \mathrm{kV}$ electrical network. The network consists of a centralized source of power $P_{S}$ equal to $40 \mathrm{MW}$, This source is connected to a load with inductive behavior through an electrical line of impedance $\mathrm{Z}=\mathrm{R}+\mathrm{jX}$, electrical study network is illustrated in figure 6 and the system data is given in appendix. A wind farm is considered to be connected to load bus and generate to the network a power $\mathrm{P}_{\mathrm{f}}$, the integration rate will be between $30 \%$ and $40 \%$. This power is intermittent and can produce voltage problems, that for whey the SSSC operation is necessary.

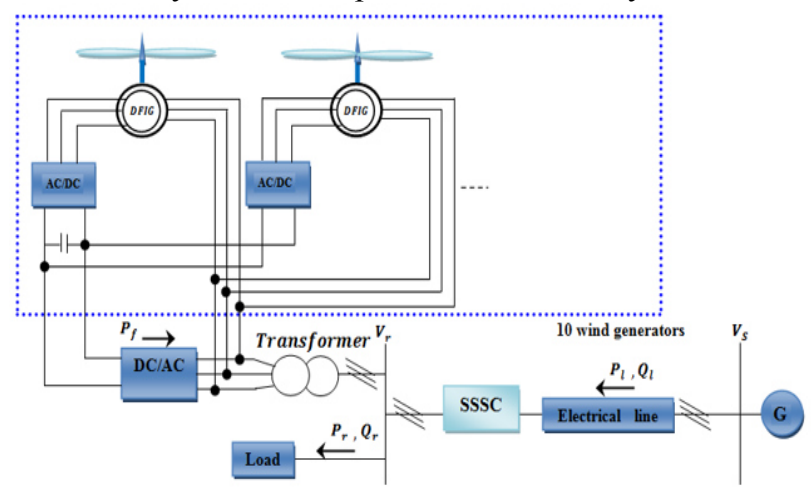

Fig. 6. Diagram of the studied system.

\section{Simulation results and discussion}

We will study the electrical network before and after integration of the SSSC in order to evaluate the contribution of the latter to power compensation, increasing power line transmission and for power oscillation damping. Figure 7 shows the active power $P_{f}$ of the wind farm. 


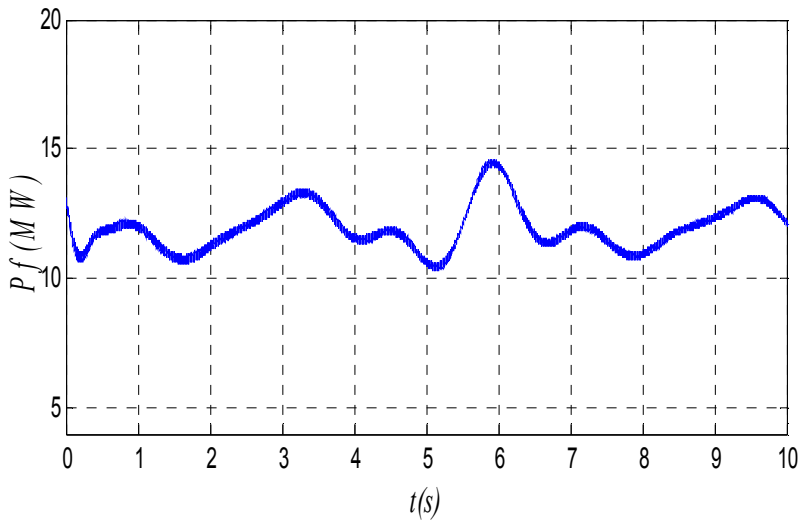

Fig.7. Active power of wind farm

Figure 8 presents the evolution of the voltage magnitudes at the source $V_{s}$, at the load node before $V_{r-b e f}$ and after $\mathrm{V}_{\mathrm{r}-\mathrm{aft}}$ compensation, the voltage became stable.

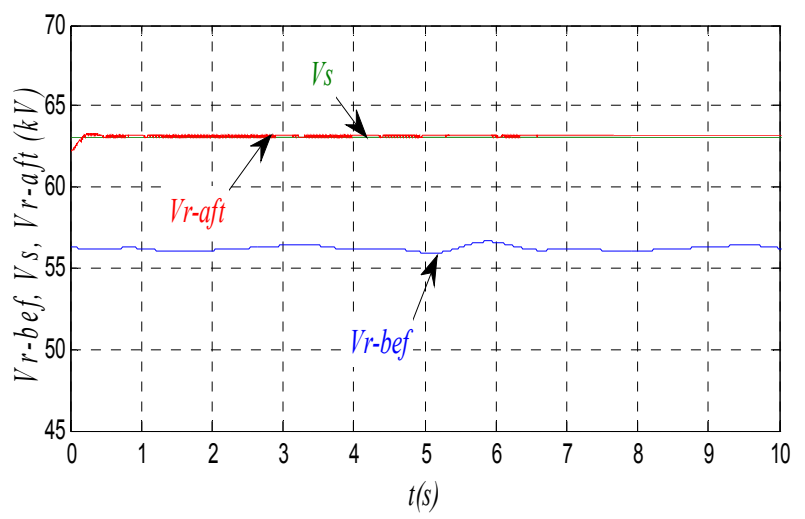

Fig.8. Voltage magnitudes at load node before and after integration of the SSSC.

Figure 9 illustrates the evolution of the active power at the load node before and after integration of the SSSC.

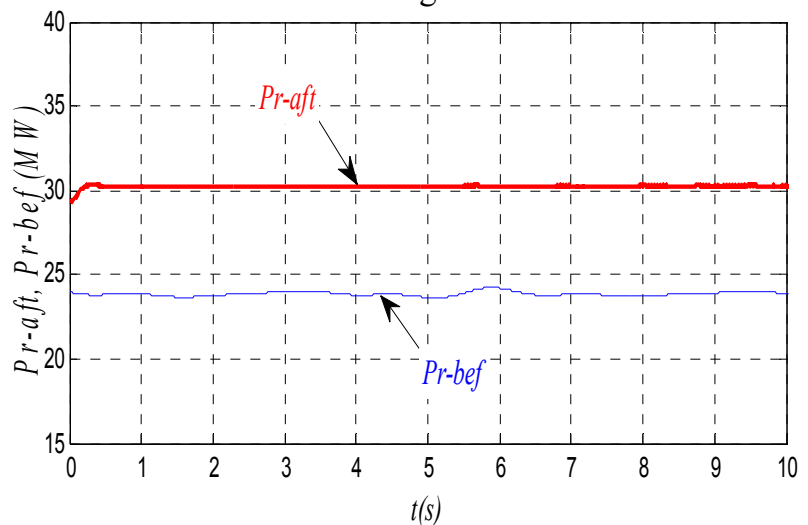

Fig.9. Power at the load node before and after integration of the SSSC.

A significant improvement of the active power losses is noted in figure 9 . We can also see through figure 8 that the voltage drop is decreased. Figure 10 illustrates the evolution of the active power flowing in the line before $\mathrm{P}_{1-\text { bef }}$ and after $\mathrm{P}_{1-\text { aft }}$ integration of the SSSC.

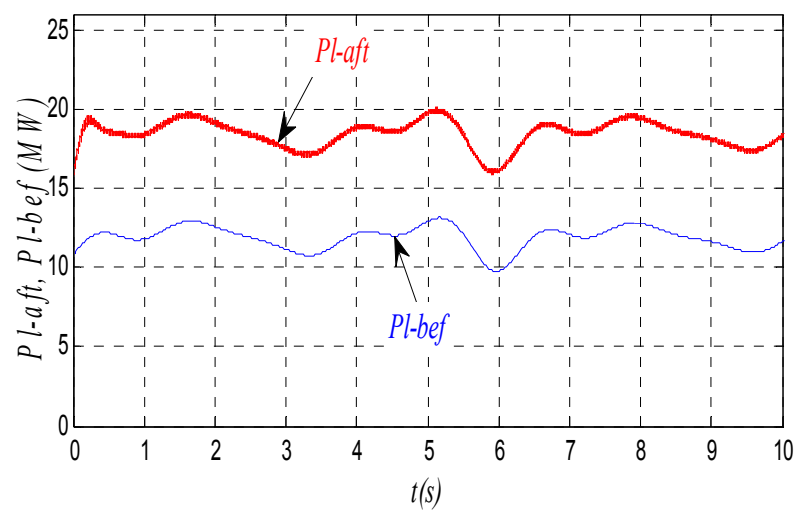

Fig.10. Active power flowing in the line before and after integration of the SSSC

Through the figure 10 it can be seen that the power transmission line is increased. The results obtained show the contribution of the SSSC to mitigate voltage drop and improve the voltage profile on the end of the electrical line as well as powers at load node.

\section{Conclusion}

In this paper, we studied the power control with SSSC for electrical network integrating wind farm based on DFIGs. The research methodology is based on the comparison of the same electrical network before and after integration of the SSSC in order to evaluate the contribution of the latter to enhance the electrical power characteristics. We have highlighted the SSSC control capability to provide best voltage level and to mitigate voltage drop. The results indicate also that the proposed control approach provide a better power oscillations damping and increase power transmission limit on the electrical network

\section{Appendix}

Wind energy conversion system parameters:

$\boldsymbol{G}=90 ; \boldsymbol{R}=37 \mathrm{~m}, \boldsymbol{f}=0.0024 \mathrm{~N} . \mathrm{m} . \mathrm{s} / \mathrm{rd}, \boldsymbol{R} \boldsymbol{s}=0.012 \Omega$,

$\boldsymbol{R} \boldsymbol{r}=0.012 \Omega, \boldsymbol{L s}=13.732 \mathrm{mH}, \boldsymbol{L r}=13.703 \mathrm{mH}$;

$\boldsymbol{M}=13.528 \mathrm{mH}, \mathrm{p}=2, \boldsymbol{P} n=1.5 \mathrm{MW}$.

Load parameters:

$\boldsymbol{P}=30 \mathrm{MW}, \boldsymbol{Q}=8 \mathrm{MVAr}$.

Line parameters:

$\boldsymbol{r}=1.015 \Omega / \mathrm{km} ; \boldsymbol{x}=6.28 \Omega / \mathrm{km} ; \boldsymbol{l}=10 \mathrm{~km} ; \boldsymbol{R}=\boldsymbol{r} . \boldsymbol{l} ;$

$\boldsymbol{X}=\boldsymbol{x} . \boldsymbol{l} ; \boldsymbol{l}=$ length of the line.

\section{References}

[1] C. Sintamarean, A. Cantarellas, H. Miranda, P. Rodriguez, et R. Teodorescu, "Smart-STATCOM control strategy implementation in wind power plants ", in 2012 3rd IEEE International Symposium on Power Electronics for Distributed Generation Systems (PEDG), 2012. 
[2] O. Aouchenni, D. Aouzellag, et N. Lahacani Aouzellag, «Voltage regulation of wind farm connected to distribution network using fuzzy supervisory control», Int. J. Sci. Eng. Res., vol. 4, n 11, 2013.

[3] C. Nichita, A. Al Ameri, «Simulation approach to improve power analysis network for integration of distributed generation", in Electrical and Power Engineering (EPE), 2014 International Conference and Exposition on, 2014.

[4] X. Liang, «Emerging power quality challenges due to integration of renewable energy sources ", in Industry Applications Society Annual Meeting, IEEE 2016.

[5] C. Anitha et P. Arul, «Enhancement of voltage stability in transmission system using SSSC », in Circuit, Power and Computing Technologies (ICCPCT), 2014 International Conference on, 2014.

[6] S. M. Abd Elazim et E. S. Ali, «Optimal SSSC design for damping power systems oscillations via Gravitational Search Algorithm », Int. J. Electr. Power Energy Syst., vol. 82 , nov. 2016.

[7] C. U. Shankar, R. Thottungal, et S. Mythili, «Stability Improvement and Power Oscillation Damping Using Static Synchronous Series Compensator (SSSC)», exchange, vol. $2, \mathrm{n}^{\circ} 1,2015$.

[8] M. G. Jolfaei, A. M. Sharaf, S. M. Shariatmadar, et M. B. Poudeh, "A hybrid PSS-SSSC GA-stabilization scheme for damping power system small signal oscillations », Int. J. Electr. Power Energy Syst., vol. 75, févr. 2016.
[9] K. Ghedamsi, D. Aouzellag, et E. M. Berkouk, "Application of matrix converter for variable speed wind turbine driving a doubly fed induction generator ", in International Symposium on Power Electronics, Electrical Drives, Automation and Motion, 2006. SPEEDAM 2006., 2006.

[10] T. Pingle, S. Patil, et S. Chopde, « Modelling and vector control of DFIG using multilevel inverter», in Advancements in Power and Energy (TAP Energy), International Conference on, 2015.

[11] P. Preetha et A. A. Kumar, "Comparsion of voltage stability using SSSC and TCSC controller», in Electronics and Communication Systems (ICECS), 2nd International Conference on, 2015.

[12] R. M. Mathur et R. K. Varma, Thyristor-based FACTS controllers for electrical transmission systems. Piscataway, NJ : New York: IEEE; Wiley, 2002.

[13] J. S. Yoon, S. Y. Kim, B. H. Chang, et D. H. Baek, «Application of FACTS technology for power system control », in 2005 International Conference on Electrical Machines and Systems, vol. 3, 2005.

[14] E. Gholipour Shahraki, «Apport de l'UPFC à l'amélioration de la stabilité transitoire des réseaux électriques ", l'UniversitY Henri Poincaré, Nancy-I, 2003. 